\title{
st \\ Quando o todo é mais sagaz do que a soma de suas partes \\ Nelson Fiedler-Ferrara
}

\author{
Emergência: a dinâmica de rede em formigas, cérebros, cidades e softwares \\ Steven Johnson \\ Tradução: Maria Carmelita Pádua Dias \\ Revisão Técnica: Paulo Vaz \\ Jorge Zahar Editor, \\ Rio de Janeiro, 2004, 231 págs.
}

\section{INTRODUÇÃO}

Steven Johnson é o jovem editor-chefe e co-fundador da Feed, uma importante revista independente disponível na Web. Com formação em semiótica (Brown University) e literatura inglesa (Columbia University), ele é considerado pela crítica americana como um mestre em fazer associações entre diferentes áreas do conhecimento e entre o cotidiano e o abstrato.

No seu livro anterior, o primeiro, Cultura da interface: como o computador transforma nossa maneira de criar e comunicar, publicado em 1977, Johnson compara, em parte, "a maneira como a arte gráfica em computador molda nossas vidas, tal como uma novela de Dickens ajudava os leitores do seu tempo para dar significado ao mundo" (Johnson, 1977, p. 2). Esse livro conferiu-lhe notoriedade entre os importantes pensadores contemporâneos do ciberespaço.

Em Emergência, os interesses de Johnson voltam-se para os chamados sistemas complexos adaptativos que mostram comportamento emergente. "Adaptativo", para o autor, significa que os comportamentos emergentes dos sistemas são tais que "reagem às necessidades específicas e mutantes de seus ambientes" (p. 15), constituindo padrões no espaço e no tempo. O foco é sobre modelos bottom-up, isto é, modelos onde não há líderes e a dinâmica se estabelece a partir de agentes múltiplos interagindo segundo regras locais, sem perceber instruções de nível mais alto. Resulta, nesses casos, algum tipo de macrocomportamento observável, o que é identificado como uma propriedade emergente. 
Sistemas complexos tão diferentes como colônias de formigas, Dictyostelium discoideum (um protista semelhante aos fungos), cidades, cérebros humanos, sistemas imunológicos, jogos de computador, "softwares" para reconhecimento de padrões, mídias e outros são utilizados pelo autor para apresentar e discutir as propriedades da emergência adaptativa; nela os agentes em uma escala produzem comportamentos identificáveis numa escala superior, como, por exemplo, formigas criam colônias.

Emergência, publicado em 2001 nos EUA e dois anos depois no Brasil, é um livro singular. A habilidade de Johnson em compor temas tão diversos permite-lhe evitar uma apresentação de conteúdos monótona e serial. Apesar da obra estar dividida em três partes, além de uma introdução bastante esclarecedora e uma bibliografia pertinente e instrutiva, os exemplos para os sistemas com emergência adaptativa são retomados várias vezes durante todo o livro. Além de Johnson apresentar uma relação dos sistemas adaptativos, tira deles o melhor proveito didático, contextualizando os modelos e os conceitos apresentados, alguns deles bastante abstratos. O resultado final é um texto legível, inclusive para não especialistas.

A apresentação dos conteúdos e as articulações que são feitas em Emergência não são apenas estimulantes e cativantes (segundo a villagevoice.com "Johnson é um crítico cultural com coração de poeta"), mas também provocativas e criativas. É um livro de divulgação científica que será apreciado pelos interessados nos novos paradigmas do conhecimento. O público em geral, bem como cientistas, intelectuais e artistas encontrarão na obra um texto fluente e bem construído, além de interpretações e especulações desafiadoras.

Johnson é hábil também em conferir dimensão humana à construção do conhecimento. Cientistas e intelectuais de renome são introduzidos através de narrativas não idealizadas dos processos de criação. Eles são apresentados imersos na esfera profissional e na vida privada, vivenciando contingências, mudanças de percurso e momentos de discernimento ou indecisão. A criação científica, o contexto social e histórico e as histórias de vida entrelaçam-se, enfatizando assim o caráter social da ciência.

Na primeira parte do livro, Johnson apresenta alguns exemplos de emergência adaptativa sem líder, que serão retomados ao longo da obra. Em cada um dos quatro capítulos da segunda parte, o autor explora os princípios centrais da emergência: interações entre vizinhos; reconhecimento de padrões, retroalimentação (feed-back) e controle indireto (discute-se aqui o papel do projetista de softwares emergentes que estabelece os limites definindo regras, mas não o macrocomportamento emergente; nesse sentido o controle é indireto). A terceira e última parte do livro é a mais especulativa da obra; nela se discute o futuro da emergência artificial numa perspectiva bottom-up. As notas, a maior parte delas transcrições de trechos de trabalhos de outros autores, são numerosas e completam o texto principal de maneira pertinente e ilustrativa. 
Antes de prosseguir, é oportuno introduzir o leitor não familiarizado a alguns dos conceitos que são trabalhados em Emergência. A seção a seguir, de caráter didático, não é propriamente uma resenha do texto de Johnson, mas busca discorrer sobre três conceitos-chave do tema para explicitar algumas conexões menos evidentes com as definições e conceitos adotados por esse autor.

\section{Complexidade, AUTO-ORGANIZAÇÃo E EMERGÊNGIA}

Complexidade designa um conjunto de conceitos, modelos e procedimentos que têm sido desenvolvidos em várias áreas do conhecimento (cf. Morin, 1977; Anderson, 1991; Nicolis \& Prigogine, 1989; Luzzi \& Vasconcelos, 1999). Nos estudos de complexidade busca-se percorrer o difícil caminho da simplicidade (reducionismo) e causalidade estrita até uma melhor representação do real, isto é, dos seres, das coisas e dos processos do mundo. De caráter multidisciplinar ou interdisciplinar, os estudos complexistas têm tratado tópicos tão diversos como "a origem da vida, a evolução das espécies, o fundamento do sistema imunológico e do sistema nervoso central [...]" (Nussenzveig, 1999, p. 9). Abordagens complexistas na física, química, biologia, medicina, economia, educação, lingüística, sociologia, literatura, artes e em outras áreas têm possibilitado a essas disciplinas alargarem os seus domínios tradicionais de abordagem. É por isso que hoje se fala numa mudança de paradigma na ciência, com conseqüências importantes para a vida do cidadão e para as formas de organização do mundo.

A complexidade preocupa-se em refletir a respeito de fenômenos nos quais há muitos agentes e interagem muitos fatores, nos quais se combinam princípios de regulação e de desequilíbrio, nos quais comparecem contingência e determinismo, criação e destruição, ordem e desordem, e nos quais podem ser identificados níveis de organização e dinâmicas não lineares marcadas por retroações entre esses níveis.

Para compreender esses níveis de organização e as retroações, pode-se tomar como exemplo a vida de um animal, que pode ser pensado, de forma simplificada, em três níveis: um largo ou superior - o animal como um todo; um nível intermediário os órgãos do animal; e um nível mais básico ou inferior - molecular ou da química do DNA. Nesse caso, um nível superior não pode ser inteiramente explicado separando os elementos que o compõem e interpretando as suas propriedades na ausência das interações que unem os elementos constitutivos desses níveis. Ou seja, a história do sistema, isto é, a vida do animal, é irredutível aos fatores estruturais.

A complexidade não é um pensamento holístico que privilegia o global sobre a análise das partes, dos seus componentes. Ele pretende articular o todo com as partes, o global e o particular num ir e vir incessantes. 
A complexidade não é complicação. Um automóvel é uma máquina bastante complicada, mas desmontável num conjunto finito de peças. Por outro lado, um organismo vivo ou um fenômeno histórico é complexo, no sentido que não pode ser decomposto e reconstruído a partir de elementos simples e independentes, sem levar em conta as retroações entre os níveis de organização.

É conveniente situar os desenvolvimentos da complexidade numa perspectiva histórica. A partir dos anos sessenta do século passado, ou mesmo a partir da década anterior, observa-se que sistemas estruturalmente idênticos podem manifestar comportamentos diferentes sob condições diversas. Começa a ocorrer, por assim dizer, o que alguns chamam (cf. Cini, 1994), apropriadamente, de renúncia à prioridade epistemológica das categorias de simplicidade, ordem e regularidade, a favor de categorias como as de complexidade, desordem e caoticidade. Note-se que isso não significa que a simplicidade, a ordem e a regularidade sejam suprimidas, mas sim que são incorporadas a uma moldura epistemológica mais larga. Em particular, verifica-se ser possível um comportamento não previsível (caótico) a partir de modelos bastante simples (com pouco grau de liberdade) representados por regras não lineares precisas (sistemas determinísticos). É o que se chama caos determinístico (cf. Ruelle, 1993; FiedlerFerrara \& Prado, 1994). Com isso, cai irremediavelmente o mito fundamental da ciência dos oitocentos: a previsibilidade da natureza.

A emergência do pensar complexo ocorrera três décadas antes, nos anos trinta do século passado, na contraposição de duas abordagens no estudo dos organismos vivos: a biologia evolutiva (herdeira da história natural) e a biologia molecular. Esta última é de cunho reducionista e tenta explicar os fenômenos biológicos a partir de eventos que se verificam no nível molecular; ela apresenta uma tendência de redução da biologia à química e à física da molécula. A biologia evolutiva - da qual emergem as idéias de complexidade - trata os organismos vivos como entidades indivisíveis; as suas particularidades específicas emergem apenas no nível da totalidade e não são dedutíveis, a não ser em alguns aspectos, da análise das subunidades constituintes.

Nas décadas seguintes ocorrem desenvolvimentos que vão constituir as bases dos sistemas complexos, resultados da interseção de várias teorias. Nos anos quarenta, a cibernética, a teoria da informação e a teoria geral de sistemas vão fornecer as bases de uma teoria da organização. Nos anos setenta, os trabalhos do físico-químico Ilya Prigogine (estudo de sistemas abertos longe do equilíbrio), do matemático von Neuman, do físico Heinz von Foerster e do médico e filósofo Henri Atlan (ordem a partir do ruído) vão fornecer os elementos de uma teoria da auto-organização. Nos anos setenta e oitenta a teoria do caos determinístico, além de conciliar determinismo e imprevisibilidade, favorecendo uma nova visão dos processos, fornecerá um arcabouço conceitual e ferramentas matemáticas originais e poderosas para tratar dos fenômenos da 
natureza e da sociedade, os quais, até então, não eram bem compreendidos. Essas teorias vão constituir os fundamentos das abordagens complexistas.

Explicitado o que se entende por sistema complexo, consideremos agora o conceito de organização. Morin (1977, p. 103-4) compreende a organização a partir de um conceito trinitário, que constitui um anel trilógico, que compreende organização, sistema e inter-relações, isto é, as três faces de um mesmo fenômeno, que ocorre a partir de interações: "não existe princípio sistêmico anterior e exterior às interações entre elementos" (Morin, 1977, p. 103). A organização - entendida como a disposição de relações entre indivíduos ou componentes que produz uma unidade complexa ou sistema dotado de qualidades desconhecidas no nível dos componentes individuais - liga, de modo inter-relacional, elementos ou acontecimentos ou indivíduos diversos, que, a partir daí, se tornam os componentes de um todo. A organização garante solidez e solidariedade relativa a essas ligações e, portanto, garante ao sistema uma certa possibilidade de duração. Toda inter-relação dotada de uma certa estabilidade ou regularidade toma um caráter organizacional e produz um sistema. A organização de um sistema - e o próprio sistema - são constituídos por inter-relações. Além disso,

os equilíbrios organizacionais são equilíbrios de forças antagônicas, assim, toda relação organizacional e, conseqüentemente, todo sistema, comporta e produz antagonismo e, ao mesmo tempo, complementaridade [seja entre as partes ou entre as partes e o todo]: toda relação organizacional necessita e atualiza um princípio de complementaridade, e necessita e mais ou menos virtualiza um princípio de antagonismo (Morin, 1977, p. 118-9).

Claramente, os antagonismos supõem a existência de forças de exclusão, de repulsão, de dissociação, que são, entretanto, superadas ou contidas pelas forças de atração, afinidades, ligações, comunicações, de tal maneira que as segundas controlam (virtualizam) as primeiras. É assim que parece fecundo entender a organização. Existe uma tensão contínua entre as complementaridades e os antagonismos (virtuais ou em atualização). É essa tensão que vai constituir a organização e o sistema, nutridos através das inter-relações.

O conceito de auto-organização está relacionado com a aptidão reorganizadora dos sistemas complexos. Ele começa a ser empregado em meados dos anos cinqüenta do século passado, em biologia, em conexão com problemas relacionados à organização espontânea, em particular, a emergência de vida a partir da matéria inorgânica e a complexificação dos organismos vivos ao longo da evolução.

Grosso modo, não há sistemas auto-organizadores, mas sim comportamentos auto-organizadores. Conforme assinala Varella, 
a auto-organização é uma descrição de um comportamento, ela tem um valor heurístico e permite indicar um fenômeno: ela é condenada a permanecer uma simples descrição, caso não nos preocupemos em pesquisar os mecanismos que estão na sua origem (1989, p. 197).

A discussão desses mecanismos é geralmente feita nos vários âmbitos disciplinares, nos quais são propostas concepções para auto-organização. ${ }^{1}$

Apesar de não ser fácil dar uma definição rigorosa para auto-organização (cf. Luzzi \& Vasconcelos, 1996, p. 199), uma possível definição foi proposta por Debrun $(1996$, p. 4):

Uma organização ou "forma” é auto-organizada quando se produz a si própria. Há auto-organização cada vez que o advento da reestruturação de uma forma, ao longo de um processo, se deve principalmente ao próprio processo - e características nele intrínsecas - e só em grau menor às suas condições de partida, ao intercâmbio com o ambiente ou à presença eventual de uma instância supervisora (Debrun, 1996, p. 4; grifo meu).

Essa definição é completada, no mesmo trabalho ( Debrun, 1996, p. 10-3), por duas definições auxiliares: auto-organização primária - quando não há um supervisor nem uma finalidade imanente (as possíveis finalidades situam-se no nível dos elementos); auto-organização secundária - quando há uma supervisão hegemônica, mas não dominante. No primeiro caso, a auto-organização “não parte de uma 'forma' (ser, sistema etc.) já constituída, mas, ao contrário, há ‘sedimentação’ de uma forma”; a interação, com eventual integração, se realiza com predominância de elementos totalmente distintos. Por outro lado, a auto-organização secundária não parte de elementos simples, mas de um sistema já constituído; nesse caso, a interação leva à "reestruturação, por 'complexificação', de uma forma já existente”. Assim, as colônias de formigas, fornecidas como exemplo de comportamento auto-organizador por Johnson em Emergência, correspondem a processos de auto-organização primária. Já a dinâmica das cidades constitui exemplo de auto-organização secundária.

Afirmou-se antes que os sistemas complexos apresentam uma organização interna estruturada em uma hierarquia de níveis caracterizada por propriedades não redutíveis àquelas do nível mais elementar. Como conseqüência, a dinâmica de tais sistemas é constituída por cadeias causais circulares (anéis recursivos) que fazem

1 Para a exploração do conceito de auto-organização em vários âmbitos disciplinares sugere-se Debrun (1996), Ottaviano \& Gonzáles (2000) e demais referências citadas. 
retroagir reciprocamente níveis superiores com os inferiores. Confere-se, dessa maneira, um caráter auto-referencial a esses sistemas.

No plano da lógica formal, a auto-referência produz paradoxos; no mundo dos objetos reais produz-se, como solução dos paradoxos, a emergência de novas estruturas e propriedades que se manifestam em comportamentos auto-organizativos: "os processos recorrentes precisam estar presentes para que os elementos autônomos [do sistema], em suas atividades, se integrem em uma organização com auto-referência" (Bresciani Filho \& Ottaviano, 2000, p. 302). Dessa maneira, a auto-organização necessariamente se dá através de uma dinâmica de retro-alimentações.

O conceito de emergência é mais sutil. Como se afirmou antes, Johnson relaciona propriedade emergente com o aparecimento de um macrocomportamento observável. Apesar de correto, é pertinente aprofundar-se essa visão com o conceito de quebra de simetria, como faz Anderson (1991, p. 9), ou seja, "a habilidade de uma coleção grande de objetos simples abandonar sua própria simetria, bem como as simetrias das forças que a governam para exibir a 'propriedade emergente' de uma nova simetria”, que se manifestará, como afirma Johnson, num novo macrocomportamento observável.

Um outro autor (Steels, 1994) distingue entre emergência de primeira ordem e emergência de segunda ordem. No primeiro caso, o sistema exibe propriedades não inerentes em seus componentes. A emergência de segunda ordem é definida como uma "propriedade emergente que confere funcionalidade adicional ao sistema, especialmente uma funcionalidade que aumenta a habilidade do sistema para processar informação" (Hayles, 1996, p. 139). Na definição adotada por Johnson, a complexidade emergente com adaptação corresponde à emergência de segunda ordem de Steels.

Em geral, os fenômenos de emergência estudados comparecem numa situação de auto-organização; daí esses termos serem usados, como o faz Johnson, de forma quase sinonímica:

Num sentido largo, o conceito de auto-organização descreve a habilidade de sistemas, compreendendo muitas unidades e sujeitos a vínculos, organizaremse, por si próprios, em padrões espaciais, temporais e espaço-temporais. Essas propriedades emergentes são pertinentes ao sistema como um todo e não podem ser vistas nas unidades que compõem o sistema (Babloyantz, 1991, p. ix).

Mas como se estuda a complexidade? As abordagens complexistas se dão, basicamente, segundo duas vertentes. Uma delas opera por meio da construção de medidas sistêmicas para a complexidade. Nessa, o objetivo é definir uma medida eficiente de complexidade de um objeto, processo ou sistema, sem conhecer seus detalhes organizativos ou funcionais. A complexidade é identificada como informação que falta, 
necessária para se obter uma explicação completa da formação do sistema e do seu funcionamento (cf. Pessoa Júnior, 1996).

A outra maneira pela qual se busca tratar a complexidade é por meio de modelos. Nesse caso, a complexidade é uma propriedade intrínseca independente do conhecimento maior ou menor que um observador externo possa ter dos detalhes do sistema. A complexidade, nessa vertente, não desaparece quando o funcionamento do sistema pode ser reconstruído a partir de suas partes. O objetivo é definir as condições estruturais necessárias para identificar um sistema como complexo. Essas diferentes definições são fornecidas por modelos para complexidade, aplicáveis, em geral, cada um, a situações e problemas específicos. A teoria do caos determinístico, as estruturas dissipativas de Prigogine, os modelos para a dinâmica de populações, os modelos de percolação e outros são exemplos de modelos para a complexidade.

Em Emergência, Johnson não considera as medições para a complexidade, mas sim os modelos para o comportamento complexo: agentes interagindo segundo regras locais e produzindo emergência adaptativa.

Após esta longa digressão, cuja finalidade foi precisar ao leitor o contexto conceitual no qual Johnson produz seu livro, retoma-se, a seguir, as considerações sobre Emergência .

\section{O TODO E AS PARTES}

Uma premissa correta de Johnson (p. 16) é que a história da emergência encontra-se em uma nova fase nos últimos anos, quando se começa a construir sistemas emergentes, com conseqüências profundas na modificação do mundo: "nossa vida cotidiana está sendo invadida pela emergência artificial”. Essa fase da história da emergência constitui o núcleo do livro, segundo o autor.

As duas fases anteriores são: inicialmente, as indagações para "entender as forças da auto-organização", sem imaginar o que fossem; uma segunda fase, "quando a auto-organização torna-se objeto de estudo".

Para Johnson, na fase atual, "paramos de analisar o fenômeno da emergência e passamos a criá-lo" (p. 16; grifo meu). Há nessa afirmação um evidente equívoco, para o qual o leitor deve estar atento. Não há dúvidas de que se está construindo sistemas emergentes e que os trabalhos em desenvolvimento são muito relevantes e colaboram de forma efetiva para as pesquisas fundamentais na área. De fato, é cada vez menos nítida a separação entre pesquisa aplicada e fundamental. Entretanto, deve ficar claro que apenas se começa a compreender alguns aspectos do fenômeno da emergência, com a necessidade de esforços teóricos e experimentais adicionais vigorosos para o aprofundamento dessa compreensão. É na física, área ausente no livro de Johnson, 
que os desenvolvimentos mais significativos do ponto de vista fundamental têm sido obtidos, particularmente em física da matéria condensada, física estatística, instabilidades dinâmicas e caos determinístico. Progressos também têm sido buscados, com resultados significativos, na biologia e no campo da inteligência artificial com abordagens conexionistas, entre outros.

O fato de que é possível desenvolver sistemas emergentes artificiais, ao mesmo tempo em que as pesquisas fundamentais são feitas, é, conforme afirmamos antes, algo positivo. Ao contrário do que afirma Johnson, esta terceira fase da história da emergência é a de coexistência entre desenvolvimentos fundamentais, para a melhor compreensão e utilização dos sistemas emergentes, e aplicações.

Johnson é mobilizado em Emergência pela questão central de "como tornar um sistema de auto-organização mais adaptativo" (p. 16).

Apesar dessa questão não ser respondida no livro - de fato esse é um problema ainda em aberto, como discutiremos mais à frente - Johnson enuncia, acertadamente, cinco princípios fundamentais (p. 57-8) para a construção de um sistema que aprende a partir de um nível mais baixo com regras locais. Assinale-se que os princípios enunciados por Johnson não são originais, como talvez o leitor sem formação especializada poderia supor. Como mostra Anderson (1991), eles têm sido usados, pelo menos desde meados dos anos oitenta, no estudo da emergência na física, particularmente na física da matéria condensada e na física estatística.

(1) Observar que é necessária uma massa crítica de agentes para produzir registros confiáveis do estado global do sistema. Perceber que micromotivos (locais) e macrocomportamentos são diversos: "somente pela observação de todo o sistema em ação é que o comportamento global se manifesta".

(2) As partes dos sistemas emergentes não devem ser excessivamente complicadas: "é melhor construir um sistema com elementos simples densamente interconectados".

(3) Interações aleatórias de agentes são desejáveis.

(4) Os agentes do sistema devem estar dotados de habilidade para detectar padrões, "o que permite a circulação de metainformação (sinais acerca de sinais)". (Neste aspecto, é pertinente recordar Bateson (1980) que define a unidade elementar de informação como a "diferença que cria diferença”. E, ainda, Steels (1994), que associa a emergência de segunda ordem (emergência adaptativa de Johnson) com a habilidade do sistema "desenvolver a capacidade de desenvolver".)

(5) Os agentes do sistema devem estar dotados da capacidade de interagir com os vizinhos: "informação local pode levar à sabedoria global". Junto com uma massa crítica de agentes (princípio 1), isso favorece a adaptabilidade do sistema. 
Esses princípios constituem uma base para a construção de sistemas emergentes adaptativos. Como tornar um sistema auto-organizado mais adaptativo é uma questão difícil de ser trabalhada, uma vez que envolve a necessidade de saber como proceder a otimizações que permitam definir as "dosagens" adequadas dos elementos incluídos (massa crítica, densidade de interconexão, nível de aleatoriedade, eficiência na capacidade de discernir padrões, nível de interação com vizinhos) em cada um dos princípios fundamentais. E isso não se sabe como fazer.

É muito provável que nunca se disponha de uma receita a partir de primeiros princípios, à maneira das teorias de base reducionista. É possível que cada caso deva ser tratado individualmente através de procedimentos que incluam fundamentação teórica juntamente com experimentação na base de ensaio e erro. Vale a pena assinalar algo similar, apesar de em outro contexto. Prigogine, ao estudar as estruturas dissipativas - estados auto-organizados longe do equilíbrio termodinâmico em sistemas abertos -, conclui pela impossibilidade de estabelecer um princípio geral válido para todos os sistemas, como ocorre na dinâmica próxima do equilíbrio, na qual vale um princípio de mínima entropia local, às custas de um aumento da entropia total (coerente com o segundo princípio da termodinâmica). No caso das estruturas dissipativas, cada sistema particular deve ser estudado particularmente usando as ferramentas da teoria dos sistemas dinâmicos, da teoria do caos e da termodinâmica longe do equilíbrio. Ainda, referindo-se à termodinâmica longe do equilíbrio, Johnson equivoca-se quando afirma que "na termodinâmica do não equilíbrio [...] as leis da entropia ficam temporariamente superadas"(p. 38). Com efeito, o segundo princípio da termodinâmica continua válido: a entropia total sempre aumenta num processo irreversível.

\section{O FUTURO DA EMERGÊNCIA ARTIFIGIAL}

Na parte final de Emergência, a mais especulativa e polêmica do livro, Johnson compartilha com o leitor algumas crenças e levanta questões bastante amplas, para as quais ainda não há respostas definitivas.

Duas dessas questões são menos genéricas e especulativas. Uma diz respeito à possível aplicação dos princípios da emergência nos sistemas corporativos (p. 167). Isso significaria uma mudança do papel da alta administração, de tal maneira que ficasse "menos preocupada em estabelecer uma direção para a companhia e mais envolvida com a motivação dos grupos que geram idéias melhores". Nesse caso, afirma Johnson, "a administração superior simplesmente prevê o mecanismo de feedback sob a forma de bônus, opções ou recursos incrementados - garantindo que os grupos mais produtivos prosperem". Parece, entretanto, lícito questionar a visão do autor: 
não seria tal sistema uma forma disfarçada de dinâmica up-down, dado o controle exercido pela alta administração sobre os fatores financeiros, que são de absoluta relevância para todos os agentes envolvidos?

A outra questão diz respeito ao futuro dos movimentos políticos, eventualmente remodelados a partir da inteligência distribuída. Argumenta o autor (p. 169) que "se você está tentando lutar contra uma rede distribuída como o capitalismo global, é melhor mesmo se tornar uma rede distribuída". Entretanto, adverte Johnson: "uma colônia de formigas sem regras locais não tem chance de criar uma ordem de nível superior [...] os movimentos antiglobalização estão somente começando a imaginar as regras apropriadas de engajamento entre as diferentes células". Conclui o autor afirmando que "os ativistas anti-OMC estão fazendo algo profundo, mesmo nesses primeiros dias de movimento. Estão pensando como um enxame”.

Três outras questões levantadas pelo autor são:

\begin{abstract}
Será que computadores - ou redes de computadores - vão se tornar autoconscientes nos próximos anos usando a abertura adaptativa do software emergente? Será que existe um quarto estágio na rede em desenvolvimento da emergência que nos leve para além dos leitores da mente, para algo mais parecido com a vida? Será que existe um genuíno cérebro global no nosso futuro e será que nos reconheceremos nele quando ele chegar? (p. 174; grifo meu).
\end{abstract}

Essas questões não são bem postas: "autoconsciência", "parecer-se com a vida" e "genuíno cérebro global" são termos vagos no contexto dos sistemas trabalhados no livro; são conceitos que não se sabe ainda bem definir na atual fase do conhecimento.

Johnson constrói alguns cenários para o futuro. Segundo o autor,

estamos começando a criar aplicações de softwares que são capazes de desenvolver uma teoria de nossas mentes. Todos esses programas auto-organizáveis, fluídos, que fazem um levantamento de nossos gostos e interesses e os medem com relação ao comportamento de grandes populações, esses programas são o começo de uma progressão que, em questão de anos, levará a um mundo em que podemos interagir regularmente com uma mídia que parece nos conhecer de um modo fundamental. O software reconhecerá nossos hábitos, antecipará nossas necessidades, adaptar-se-á a nossas mudanças de humor (...) o novo software usará ferramentas de auto-organização para construir modelos de nossos próprios estados mentais (p. 153; grifo meu).

Ou ainda, 
a emergência aplicada irá além da simples construção de aplicações amigáveis. Ela transformará nossa própria definição de experiência com a mídia e desafiará muitas de nossas habituais suposições sobre a separação entre a vida pública e a privada (p. 154; grifo meu).

Johnson omite no livro qualquer discussão de natureza ética e de valores com relação a esses cenários. Seria desejável que isso tivesse sido feito; com efeito, tais cenários, se confirmados, conduziriam a uma sociedade muito diferente da atual, com conseqüências importantes para a vida dos cidadãos.

Por outro lado - de maneira um tanto contraditória para alguém que parece ter uma postura pouco crítica com relação a uma sociedade onde uma mídia "parece nos conhecer" -, o autor demonstra entusiasmo por uma "política da emergência" com auto-organização adaptativa dos movimentos sociais, cujas primeiras manifestações, segundo o autor, estiveram nos protestos de Seattle em 1999 contra a Organização Mundial do Comércio.

\section{Desafio PARA REPENSAR O MUNDO EM TORNO DE NóS}

As idéias sobre complexidade e emergência são recebidas positivamente quando introduzidas a quem não as conhece. As audiências que entram em contacto com elas alunos de todos os níveis, professores e o público em geral, para os quais tenho falado sobre esse tema há mais de uma década - afirmam, com muita freqüência, que essas idéias modificaram a maneira como elas vêem o mundo. Isso ocorre porque os modelos para complexidade e emergência são significativos para os indivíduos, na medida em que são consistentes com as percepções que se tem do mundo: padrões no espaço e no tempo em constante mutação. Os modelos de base reducionista, apesar de eficientes em muitas situações e base da maior parte da tecnologia contemporânea, estão muito longe da maneira como o mundo é percebido pelos sentidos.

Algo similar ocorre quando se lêEmergência. Um usuário da <amazon.com>, numa resenha que fez do livro de Johnson, refere-se a ele como um "livro que desafia para repensar o mundo em torno de nós". Em <kottke.org>, o editor refere-se ao livro "não como um marco, mas um livro que o deixou excitado para pensar a respeito do mundo".

Concordo com essas opiniões. Não se fica imune a Emergência. Além do fascínio exercido pelo tema, há no livro uma maneira sedutora e desafiadora de escrever. Ao leitor não é permitida uma postura passiva. Ele é chamado a participar, a concordar ou discordar, a descobrir ou especular junto com o autor. 
Johnson, em uma entrevista a <oreillynet.com>, refere-se aos sistemas complexos com emergência adaptativa como aqueles "onde o todo é mais sagaz do que a soma de suas partes [...] aparecendo, a partir de interações simples de nível mais baixo de milhares ou milhões de agentes, alguma estrutura de nível mais alto ou inteligência" (grifo meu).

Esses antropomorfismos - "sagaz" e "inteligência" - são metáforas da "alma de poeta de Johnson". Muitos colegas cientistas protestariam veementemente pelo seu uso. Entretanto, pode-se compreender o que o autor está pretendendo dizer. O leitor pode fazê-lo. Talvez, nessa sensibilidade do autor resida parte do sucesso de Steven Johnson ao conseguir transmitir com clareza os conteúdos desse seu "livro complicado e multifacetado" (p. 217), como ele próprio o define.

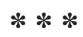

Acredito que o pensar complexo possa se constituir no núcleo de uma mudança de paradigma em ciência. Parte significativa da ciência que é feita hoje não atende às necessidades do nosso tempo. Não o faz porque está sufocada pela especialização excessiva que limita a criatividade. Não o faz porque é regida pela lógica perversa de mercado. Não o faz porque está demasiado afastada do concreto, da complexidade do real. Não o faz porque não se tem ocupado suficientemente em resolver problemas que possam melhorar a condição de vida de centenas de milhões de deserdados e famintos no mundo. Não o faz porque está cega, submetida aos poderosos, porque a maioria dos cientistas tem feito vistas grossas aos problemas sociais e lutam sobretudo por prestígio pessoal e recursos para si e para seus projetos, corroborando, algumas vezes, aquilo que o saudoso Maurício Tragtenberg (1979) denominou "delinqüência acadêmica" ou "traição do intelectual". Não o faz porque desconsidera os graves problemas de desequilíbrio do meio ambiente causado por um sistema econômico insano. O pensar complexo, é verdade, traz em seu bojo ferramentas novas e poderosas para tratar os problemas do mundo real. Existe, é verdade, esperança de que esse pensar seja mais aberto às mudanças, à criatividade, ao benefício das dúvidas e incertezas que possam contribuir para reduzir a absurda autocomplacência e cegueira dos poderosos e de seus cúmplices. É, sem dúvida, fascinante e estimulante participarmos de um tempo de mudança de paradigma, depois de vários séculos de hegemonia cartesiana. Vivemos, contudo, uma situação nova. Não se trata de substituir o reinado do cartesianismo pelo reinado complexista, mas de compor harmoniosamente aquilo que viemos aprendendo em diferentes culturas ao longo dos séculos. Mas para quê? Para nos deliciarmos, 
ainda uma vez, pela nossa inteligência? Festejarmos, ainda uma vez, a supremacia do Homo sapiens num universo cujas fronteiras no macroscópico e no microscópico estão se alargando? O que faremos com o Homo demens dentro de cada um de nós? Faremos de conta que ele não existe? Não. Desta vez precisamos mais do que especialistas e técnicos competentes. Necessitamos mais do que intelectuais brilhantes. Teremos também de empreender uma profunda mudança em nossas mentes e em nossas atitudes. Essa mudança se faz necessária pela gravidade da situação em que vivemos. É nesse sentido que devemos trabalhar e formar as novas gerações. Nossos esforços devem ser na direção da construção de um novo paradigma - seja ele o complexista ou qualquer outro ao qual nos conduzamos através do processo histórico-cultural - que colabore para a felicidade e a harmonia dos seres numa relação de amor recíproco e pela natureza. Contudo, estejamos cientes de que esse processo histórico-cultural é produzido a partir de nossas ações. Por isso, fiquemos atentos a elas e à nossa responsabilidade.

\author{
Nelson Fiedle R-Ferrara \\ Professor Associado do Instituto de Física \\ da Universidade de São Paulo. \\ ferrara@if.usp.br
}

\title{
REFERÊNGIAS BIBLIOGRÁFIGAS
}

Anderson, P.W. Is complexity physics? Is it science? What is it? Physics Today, 44, 7, p. 9-10, 1991.

Bateson, G. Vers une ecologie de l'esprit. Paris, Seuil, 1980. v. 2. p. 205-22.

Babloyantz, A. (Ed.). Self-organization, emerging properties and learning. New York, Plenum Press, 1991. Introdução. In: (Ed.). Self-organization, emerging properties and learning. New York, Plenum Press, 1991. p. ix-xv.

Bresciani Filho, E. \& Ottaviano, I. M. de. Conceitos básicos de sistêmica. In: Ottaviano, I. M. de \& Gonzáles, M. Q. E. (Ed.). Auto-organização: estudos interdisciplinares. Campinas, Edunicamp, 2000. p. 283-3o6.

Ginı, M. Il paradiso perduto: dall'universo delle leggi naturalial mondo dei processi evolutivi. Milano, Feltrinelli, 1994.

Debrun, M. A idéia de auto-organização. In: ___ Gonzáles, M. E.Q. \& Pessoa Júnior, O. (Ed.). Autoorganização. Campinas, Edunicamp, 1996. p. 4-23.

; Gonzáles, M. E. Q. \& Pessoa Júnior, O. (Ed.). Auto-organização. Campinas, Edunicamp, 1996. (Coleção Gle, 18).

Fiedler-Ferrara, N. \& Prado, C. P. C. Caos: uma introdução. São Paulo, Edgar Blücher, 1994.

Hayles, N. K. From self-organization to emergence: aesthetic implications of shiftings ideas of organization. In: Herbert, D. E. (Ed.). Chaos and the changing nature of science and medicine: an introduction. Woodbury, American Institute of Physics, 1996. p. 133-57. 
Herbert, D. E. (Ed.). Chaos and the changing nature of science and medicine: an introduction. Woodbury, American Institute of Physics, 1996.

Johnson, S. Interface culture. Hownew technology transforms the way we create and communicate. San Francisco, Harper Edge, 1977.

Luzzi, R. \& VAsconcelos, A. R. Estruturas dissipativas auto-organizadas: um ponto de vista estatístico. In: Debrun, M.; Gonzáles, M. E. Q. \& Pessoa Júnior, O. (Ed.). Auto-organização. Campinas, Edunicamp, 1996. p. 191-237.

\& __. Algumas considerações sobre complexidade, auto-organização e informação. Campinas, Instituto de Física Gleb Wataghin, 1999.

Morin, E. O método. Portugal, Publicações Europa-América, 1977. v. 1: A natureza da natureza.

Nicolis, G. \& Prigogine, I. Exploring complexity. New York, W. H. Freeman, 1989.

Nussenzveig, H. M. (Org.). Complexidade e caos. Rio de Janeiro, Editora UFRJ/COPEA, 1999. Introdução à complexidade. In: (Org.). Complexidade e caos. Rio de Janeiro, Editora UFRJ/ COPEA, 1999. p. 9-26.

Ottaviano, I. M. de \& GonzÁles, M. E. Q. (Ed.). Auto-organização: estudos interdisciplinares. Campinas, Edunicamp, 2000. (Coleção GLe, 3०).

Pessoa Júnior, O. Medidas sistêmicas e organização. In: Debrun, M.; Gonzáles, M.E.Q. \& Pessoa Júnior, O. (Ed.).Auto-organização. Campinas, Edunicamp, 1996. p. 129-61.

Ruelle, D. Acaso e caos. São Paulo, Editora da Unesp, 1993.

Steels, L. The artificial life roots of artificial intelligence. Artificial Life, 1, p. 75-110, 1994.

Tragtenberg, M. A delinqüência acadêmica. Educação \& Sociedade, 3, p. 76-94, 1979.

VARELLA, F. Autonomie et connaisssance: essai sur le vivant. Paris, Editions du Seuil, 1989. L'auto-organisation: de l'apparence au mecanisme. In: Autonomie et connaisssance: essai sur le vivant. Paris, Editions du Seuil, 1989. p. 187-205. 